\title{
MICRO-PROCESSOR BASED TEMPERATURE CONTROLLER ON POWER TRANSISTORS
}

\author{
Mulwa P.K ${ }^{1}$, Muia L.M², Ogola W.O ${ }^{3}$ \\ ${ }^{1}$ Faculty of Engineering, Egerton University, P.O Box 11070-00400 Nairobi, Kenya \\ ${ }^{2}$ Faculty of Applied Science and Technology, Physics Department, Technical University of Kenya, P.O Box 52428 - \\ 00200 Nairobi, Kenya. \\ ${ }^{3}$ Faculty of Engineering and Technology, Technical University of Kenya, P.O Box 52428 -00200, Nairobi, Kenya
}

\begin{abstract}
Radio frequency (RF) signal amplification was considered to solve the power transistor's problems caused by temperature. The goal is to minimize power losses and maximize signal area of coverage. The problems are drift, gain loss and failures in power transistors. This is mainly caused by temperatures exceeding preset design limit. These problems lead to low radio frequency power output and white noise in output signal. Micro-Processor based temperature controller was designed to solve the problem. Experiment was carried out to determine the required air flow rate at a certain ambient temperature and power transistor temperature. Intercooled stata 8.0 software was used and gave characteristic depicting power loss and the regression coefficient $\left(r^{2}\right)$ for the independent and dependent variables. Through the research, design and testing an intelligent temperature controller monitoring both ambient air and power transistors temperature hence realizing the required ambient air flow rate was achieved. This enhanced RF power transistors to increase the power of carrier signals, increase the range of radio waves and suppress noise in the wanted signals.
\end{abstract}

Keywords: Power loss, Temperature, Drift, Gain Loss, White Noise.

\section{INTRODUCTION}

During signal transmission, heat is generated, which leads to an increase in power transistors temperature. This makes the power transistors to be pushed to the saturation point. At high temperatures transistors normally draw more current. This makes them to operate beyond cut off region causing drift, low radio frequency (RF) output power and subjecting the required signals to white/thermal noise.

The research investigated temperature effects on power transistors and tried to enhance better temperature regulation hence power losses minimized and noise signals suppresed.

\subsection{Proportional Integral Differential (PID) Control}

This controller combines proportional control with two additional adjustments which helps the unit to compensate for the changes. These adjustments, integral and derivative are expressed in time based unit. The proportional, integral and derivative terms must be individually adjusted in a system using trial and error method. The PID controllers perform poorly in some applications and do not in general provide optimal control. The fundamental difficulty with PID control is that, it is a feedback system, with constant parameters and no direct knowledge of the process. Thus the overall performance is reactive and compromise [1 -2$]$.

\subsection{Heat Sink Temperature Control}

A peltier cooling system for solid state operational amplifier reduces the bias current [3]. The sense output which is proportional to the absolute temperature of the amplifier is fed to the temperature control circuitry. The control circuit compares the sensor current with the temperature set point current and the difference is used for the control. However amplifier drift remains a problem to be solved since temperature gradient exists between a semiconductor substrate and the peltier junction [4].

\subsection{Broadcast electronics (BE) Transmitter}

\section{Temperature Control}

It's an air cooled suction blowers running at a constant speed. It acts by reducing the RF power output to stabilize the temperature [5].

\section{RESEARCH METHOD.}

\subsection{Design of Temperature Control System}

This section dealt with the actual design of the temperature control system. The section was divided into two main parts, namely:

- Hardware development

- Microcontroller software development

The hardware system was important because it did the actual implementation of the desired control. However, the software is what enabled the hardware to do what was required. 


\subsection{Hardware Development}

The hardware development consisted of the design of six blocks of the temperature control system. These parts included:

- $\quad$ The power supply

- The temperature detection system

- The man-to-machine communication interface

- The machine-to-man communication interface

- The cooling system's actuation and control mechanism

- The system control unit

Each of the blocks performed a specific function that contributed to making the entire system work as shown in Figure 2.1.

\subsection{System Control Unit}

To achieve the entire functional temperature control system, ATmega32 microcontroller, two LM35 precision centigrade temperature sensors, matrix keypad, LCD and LEDs for display and motor were used. The microcontroller is an 8-bit powerful general purpose processor with integrated peripheral features. It minimizes the need to have additional interfaces to get a fully functional control system. For example, the microcontroller comes with an inbuilt 8channel ADC with a 10-bit resolution. It also has an inbuilt noise canceller making it very immune to noise signals. With the ability to be clocked up to $16 \mathrm{MHz}$, the chip is fast enough and hence allows for temperature control.

The microcontroller also has 14 PWM modes, giving the designer a choice of PWM generation to use. In addition to the PWM channels, there is a multiplexed Input Capture Pin (ICP) which allows the system to capture signals from a tachometer directly and hence enable the system to be able to detect rate of motion of a motor or other devices. Due to availability of 32 multiplexed bidirectional input/output pins, inbuilt EEPROM memory, a large flash memory, internal and external interrupt control channels and inbuilt serial communication channels, ATmega32 was ideal as a single controller of multiple hardware systems, hence the choice $[6-8]$.

The complete circuit diagram is shown in Figure 2.1. Figure 2.2 on the other hand shows the assembled unit of the micro-processor based temperature controller.

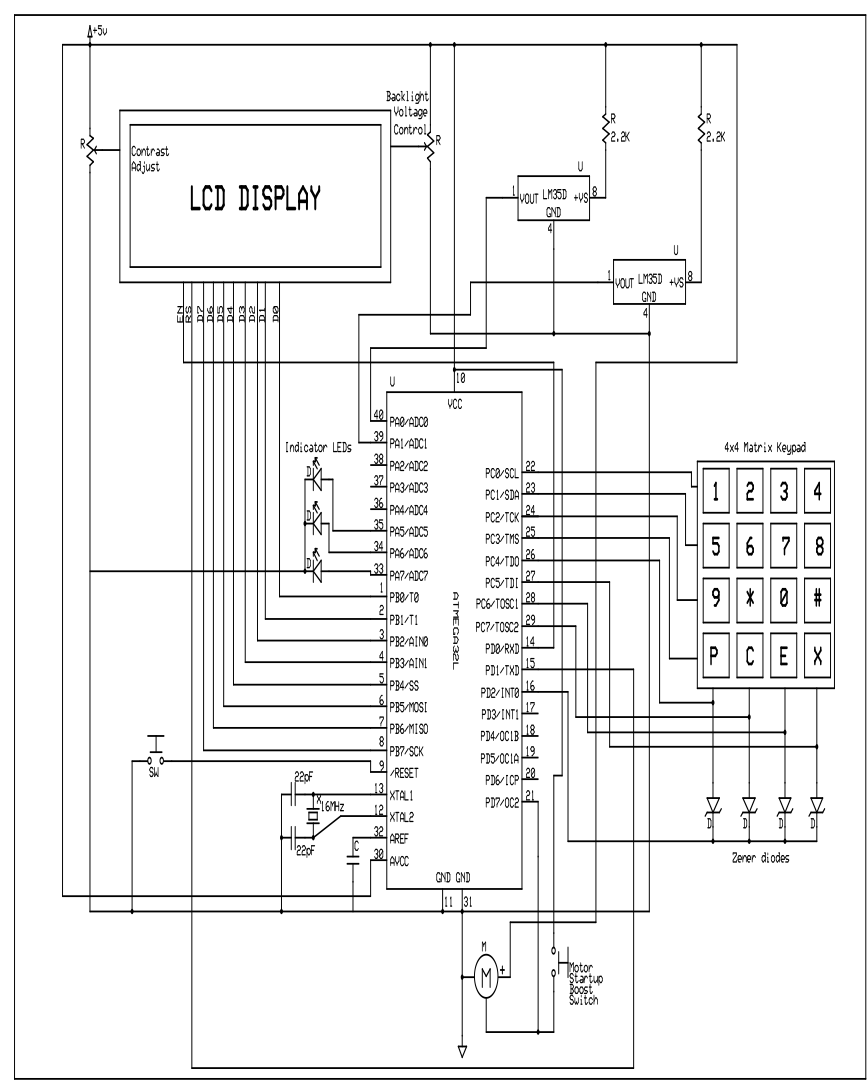

Figure 2.1 Full Circuit Diagram

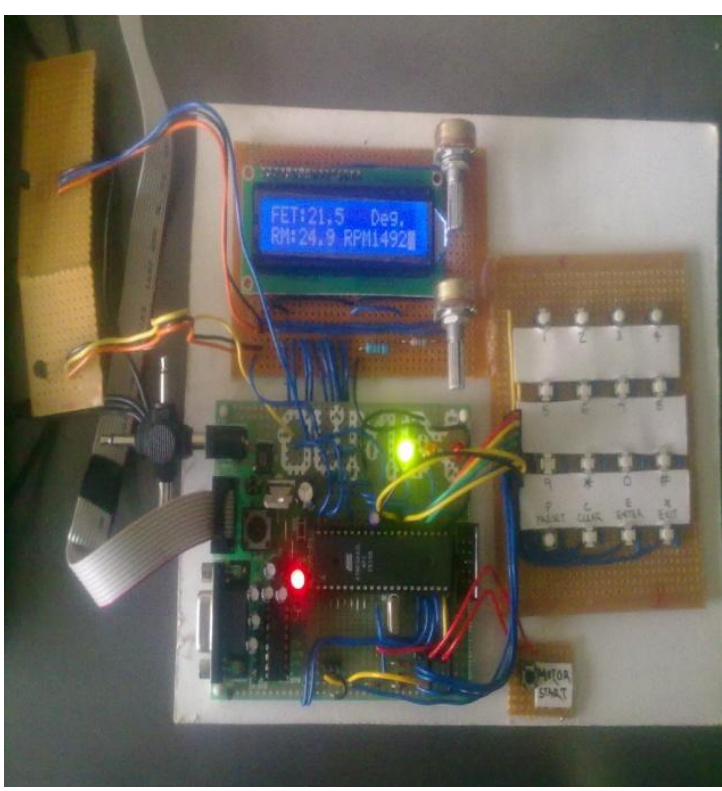

Fig 2.2 Assembled Microprocessor temperature controller

\subsection{Software Development}

The temperature control system required control software to run. This was developed using AVRStudio designed for Atmel's microcontrollers. The AVRStudio uses assembly and $\mathrm{C}$ programming languages for software development. Hence the software was mainly developed in $\mathrm{C}$ but some low-level functionality were developed using Assembly programming language. 
The software was developed in a modular manner and consisted of the following main modules

- $\quad$ System initialization code

- ADC control code for sampling temperature readings and calculating the current temperature values

- The keypad logic control code for executing commands based on keypad entries

- The LCD control code for controlling the display, in conjunction with the indicator LED software

The cooling system ON/OFF control system, speed regulation and variation of the ambient air flow rate

To achieve this it was as in the flow charts shown in figures 2.3 to 2.6 .

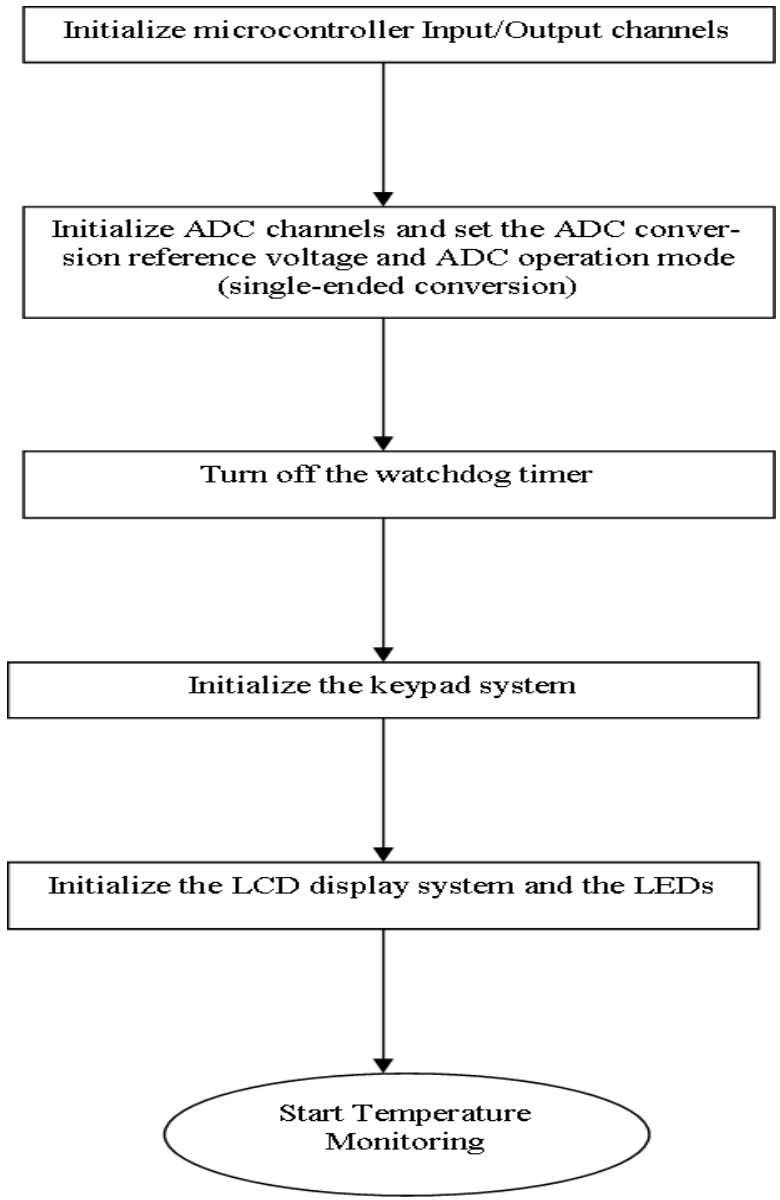

Fig 2.3 System Initialization flow chart

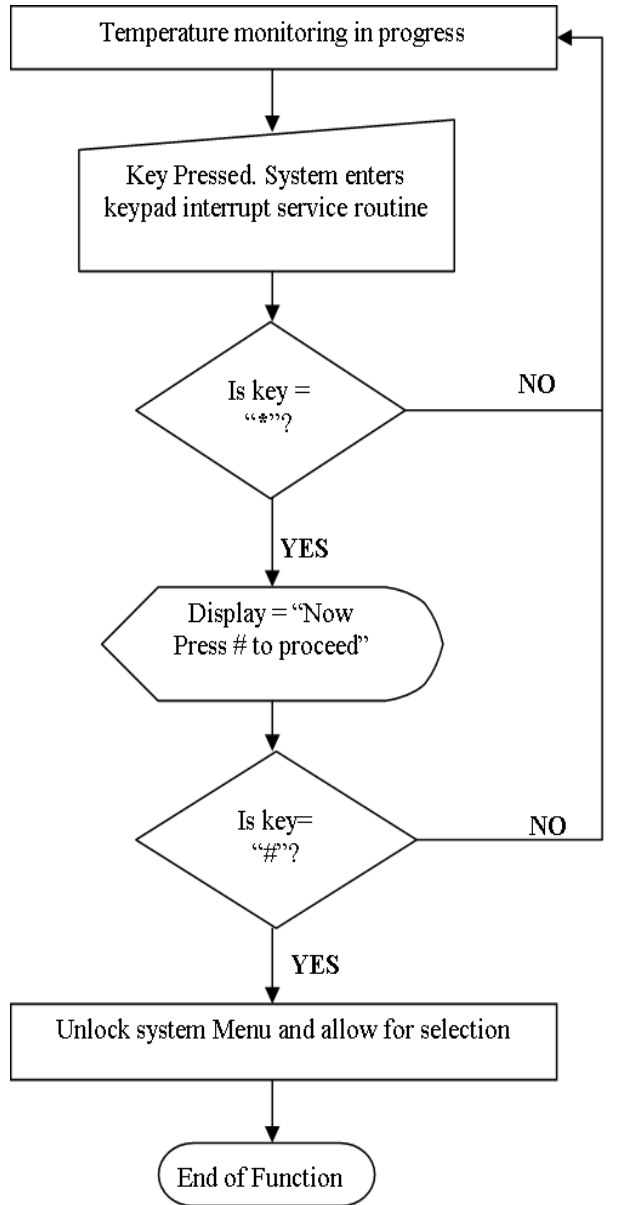

Fig 2.4 Keypad control logic flow chart

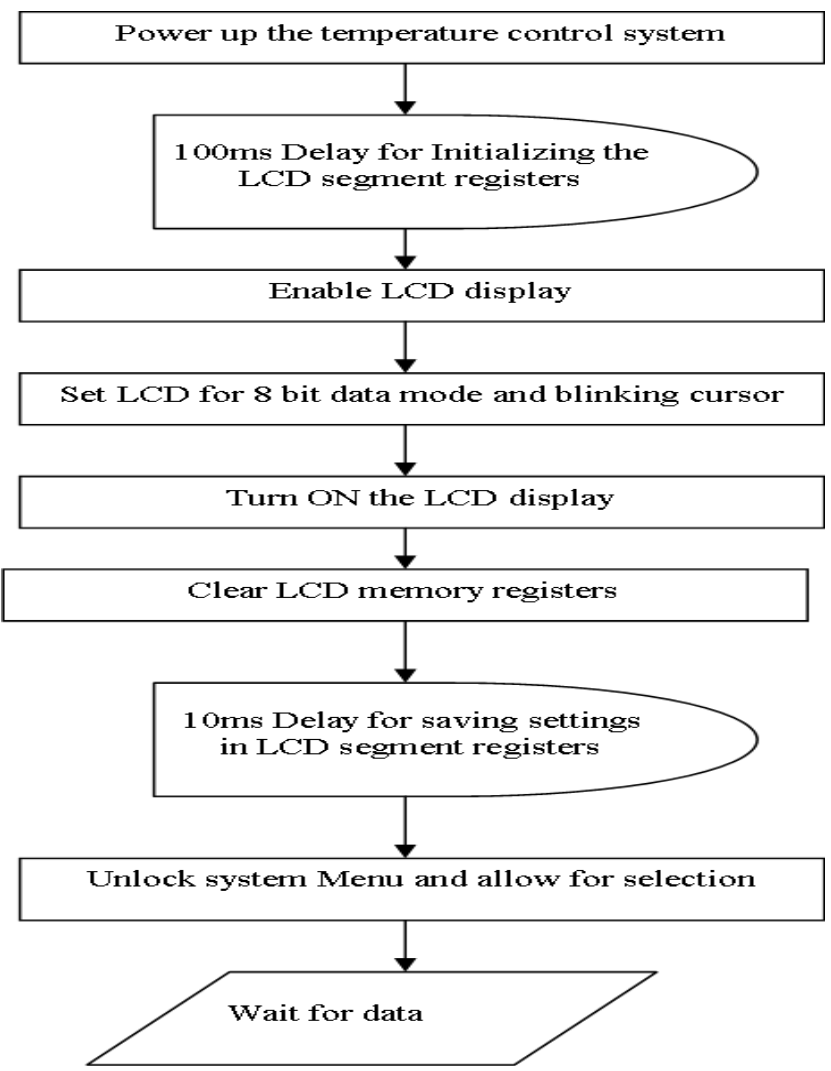

Fig 2.5 LCD display control logic flow chart 


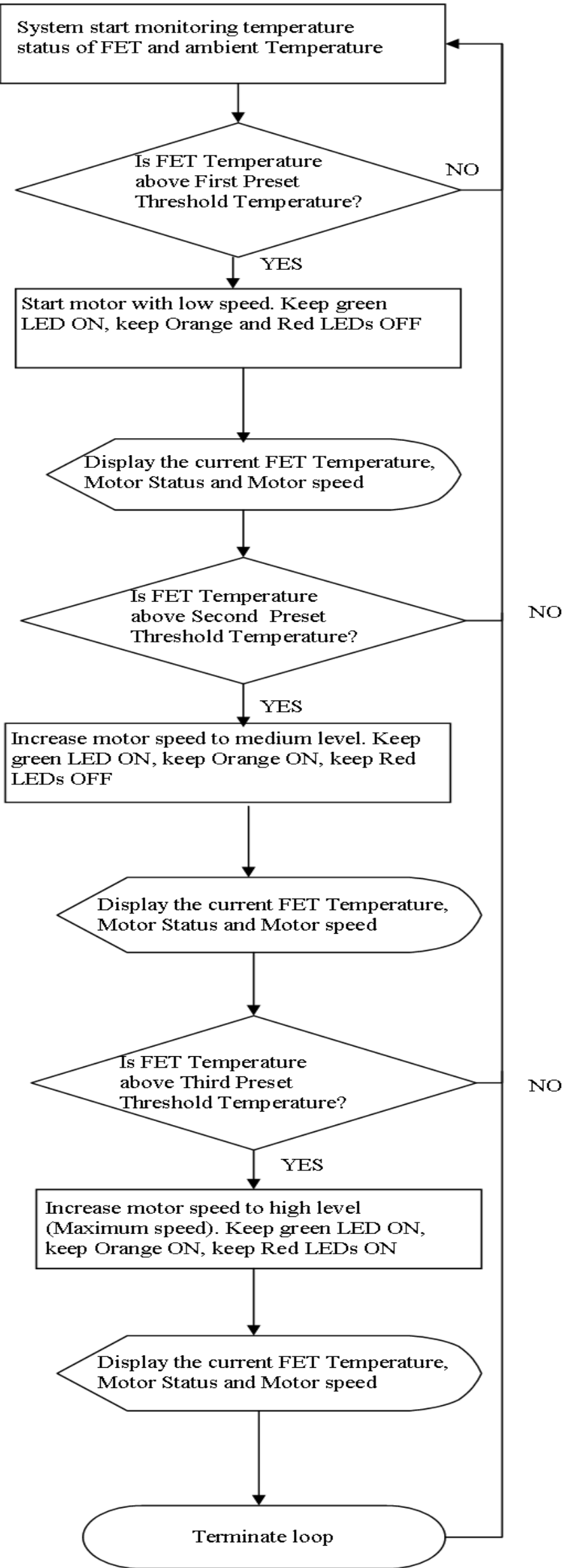

\subsection{Data Presentation}

Experiments were carried out and data collected after every half an hour at various power transistors (FET) randomly as shown in the table 2.0.

Fig 2.6 Motor speed control flow chart 
Table 2: Data Presentation

\begin{tabular}{|c|c|c|c|c|c|c|c|c|c|c|c|}
\hline \multirow[t]{2}{*}{$\begin{array}{l}\operatorname{Re} \\
\text { f. }\end{array}$} & \multirow[t]{2}{*}{$\begin{array}{l}\text { Time of } \\
\text { the day }\end{array}$} & \multicolumn{2}{|c|}{$\begin{array}{l}\text { Ambient } \\
\text { Temperature }\end{array}$} & \multirow{2}{*}{$\begin{array}{l}\text { FET } \\
\text { Temper } \\
\text { ature } \\
\text { Fan } \\
\text { speed } \\
\text { Constan } \\
\text { t }\end{array}$} & \multirow{2}{*}{$\begin{array}{l}\text { FWD } \\
\text { Powe } \\
\mathbf{r} \\
(\mathbf{K W}) \\
\text { Fan } \\
\text { speed } \\
\text { Const } \\
\text { ant }\end{array}$} & \multirow{2}{*}{$\begin{array}{l}\text { RF } \\
\text { L } \\
\text { Po } \\
\text { wer } \\
\text { (W) }\end{array}$} & \multirow{2}{*}{$\begin{array}{l}\text { Microp } \\
\text { rocesso } \\
\text { r- } \\
\text { controll } \\
\text { ed FET } \\
\text { Tempe } \\
\text { rature }\end{array}$} & \multirow{2}{*}{$\begin{array}{l}\text { Microp } \\
\text { rocesso } \\
\text { r- } \\
\text { control } \\
\text { led } \\
\text { RPM }\end{array}$} & \multirow{2}{*}{$\begin{array}{l}\text { Microproc } \\
\text { essor- } \\
\text { controlled } \\
Q\left(\mathbf{m}^{3} / \mathbf{s}\right)\end{array}$} & \multirow[b]{2}{*}{$\begin{array}{l}\text { FWD } \\
\text { power } \\
\text { (KW) } \\
\text { with } \\
\text { micropr } \\
\text { ocessor- } \\
\text { controlle } \\
\text { d FET } \\
\text { tempera } \\
\text { ture }\end{array}$} & \multirow[b]{2}{*}{$\begin{array}{l}\text { RFL } \\
\text { power } \\
\text { with } \\
\text { microproc } \\
\text { essor- } \\
\text { controlled } \\
\text { temperatu } \\
\text { re } \\
\left(\mathrm{KW} 10^{-}\right. \\
\left.{ }^{3}\right)\end{array}$} \\
\hline & & $\begin{array}{l}\text { Ther } \\
\text { mom } \\
\text { eter } \\
\text { Rea } \\
\text { ding }\end{array}$ & $\begin{array}{l}\text { LM3 } \\
5 \\
\text { Sens } \\
\text { or } \\
\text { Read } \\
\text { ing }\end{array}$ & & & & & & & & \\
\hline 1 & 7.00am & 20 & 20.4 & 21.2 & 2.0 & 2 & 21.1 & 1440 & 55.1232 & 2.2 & 2 \\
\hline 2 & 7.30am & 22 & 22.2 & 25.5 & 2.0 & 2 & 25.4 & 1700 & 65.076 & 2.2 & 2 \\
\hline 3 & $8.00 \mathrm{am}$ & 22 & 22.5 & 26.4 & 2.0 & 2 & 26.3 & 1752 & 67.06656 & 2.2 & 2 \\
\hline 4 & 8.30am & 22.5 & 22.8 & 28.4 & 2.0 & 2 & 27.3 & 1804 & 69.05712 & 2.2 & 2 \\
\hline 5 & $9.00 \mathrm{am}$ & 23 & 23.4 & 29.5 & 2.0 & 2 & 28.7 & 1856 & 71.04768 & 2.2 & 2 \\
\hline 6 & 9.30am & 23.5 & 23.8 & 31.4 & 2.0 & 2 & 30.1 & 1960 & 75.0288 & 2.2 & 2 \\
\hline 7 & 10.00am & 24 & 24.3 & 33.6 & 1.9 & 2 & 32.5 & 2064 & 79.00992 & 2.2 & 2 \\
\hline 8 & 10.30am & 25 & 25.3 & 36.1 & 1.85 & 2 & 34.9 & 2168 & 82.99104 & 2.2 & 2 \\
\hline 9 & $11.00 \mathrm{am}$ & 27 & 27.4 & 40.2 & 1.8 & 2 & 37.8 & 2324 & 88.96272 & 2.1 & 2 \\
\hline 10 & $11.30 \mathrm{am}$ & 27 & 27.3 & 42.3 & 1.7 & 2 & 39.7 & 2436 & 93.25008 & 2.1 & 2 \\
\hline 11 & $12.00 \mathrm{pm}$ & 27 & 27.4 & 45.6 & 1.65 & 2 & 41.6 & 2532 & 96.92496 & 2.0 & 2 \\
\hline 12 & $12.30 \mathrm{pm}$ & 26.5 & 26.8 & 46.4 & 1.60 & 2 & 43.1 & 2636 & 100.90608 & 2.0 & 2 \\
\hline 13 & $1.00 \mathrm{pm}$ & 25 & 25.3 & 44.6 & 1.65 & 2 & 42.1 & 2584 & 98.91552 & 2.0 & 2 \\
\hline 14 & $1.30 \mathrm{pm}$ & 25 & 25.3 & 44 & 1.65 & 2 & 41.6 & 2532 & 96.92496 & 2.0 & 2 \\
\hline 15 & $2.00 \mathrm{pm}$ & 24.5 & 24.9 & 42.8 & 1.7 & 2 & 39.2 & 2428 & 92.94384 & 2.1 & 2 \\
\hline 16 & $2.30 \mathrm{pm}$ & 24.5 & 24.8 & 39.9 & 1.75 & 2 & 37.3 & 2324 & 88.96272 & 2.1 & 2 \\
\hline 17 & $3.00 \mathrm{pm}$ & 24.5 & 24.8 & 38.9 & 1.75 & 2 & 35.9 & 2220 & 84.9816 & 2.1 & 2 \\
\hline 18 & $3.30 \mathrm{pm}$ & 24 & 24.4 & 36.5 & 1.8 & 2 & 34.9 & 2168 & 82.99104 & 2.1 & 2 \\
\hline 19 & $4.00 \mathrm{pm}$ & 24 & 24.3 & 33.2 & 1.8 & 2 & 32.1 & 2064 & 79.00992 & 2.2 & 2 \\
\hline 20 & $4.30 \mathrm{pm}$ & 24 & 24.3 & 31.7 & 1.85 & 2 & 30.6 & 1960 & 75.0288 & 2.2 & 2 \\
\hline 21 & $5.00 \mathrm{pm}$ & 23.5 & 23.7 & 30.2 & 1.85 & 2 & 29.7 & 1908 & 73.03824 & 2.2 & 2 \\
\hline 22 & $5.30 \mathrm{pm}$ & 23 & 23.4 & 28.8 & 1.9 & 2 & 28.2 & 1856 & 71.04768 & 2.2 & 2 \\
\hline 23 & $6.00 \mathrm{pm}$ & 22.5 & 22.9 & 27.3 & 1.9 & 2 & 26.8 & 1752 & 67.06656 & 2.2 & 2 \\
\hline 24 & $6.30 \mathrm{pm}$ & 22.5 & 22.8 & 26.1 & 2.0 & 2 & 25.8 & 1700 & 65.076 & 2.2 & 2 \\
\hline 25 & $7.00 \mathrm{pm}$ & 22 & 22.4 & 25.3 & 2.0 & 2 & 24.9 & 1648 & 63.08544 & 2.2 & 2 \\
\hline 26 & $7.30 \mathrm{pm}$ & 21.5 & 21.8 & 23.8 & 2.0 & 2 & 23.4 & 1596 & 61.09488 & 2.2 & 2 \\
\hline
\end{tabular}

\section{RESULTS AND DISCUSSION}

The experiment was done on different combinations in regard to the forward power. Measurements were carried out and gave the characteristics as shown in figures 3.0 to 3.2

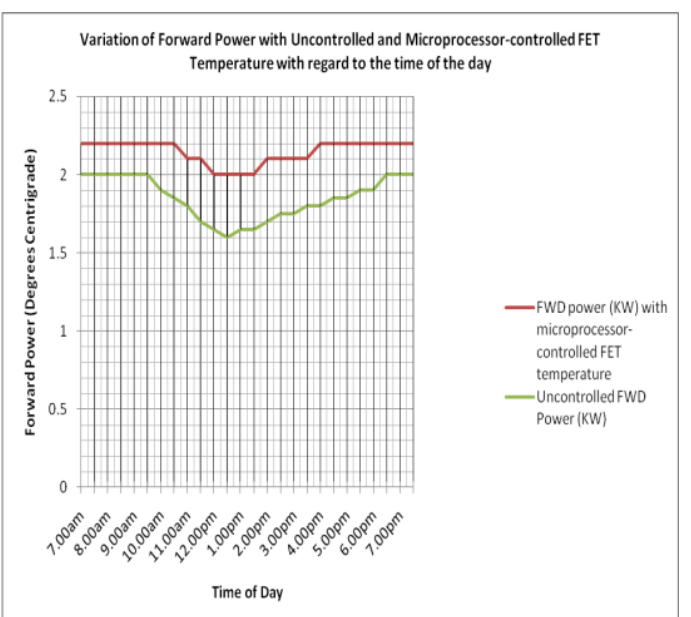

Fig 3.0: Variation of forward power with uncontrolled and microprocessor-controlled FET temperature with regard to the time of the day 
It is clear from Figure 3.0 that the microprocessor-controlled FET temperature has a lower recovery time and higher forward power compared to when the FET temperature is controlled unintelligently.

Using Intercooled STATA 8.0, the characteristics depicting the power loss were as shown in Figure 3.1 and 3.2 [9].

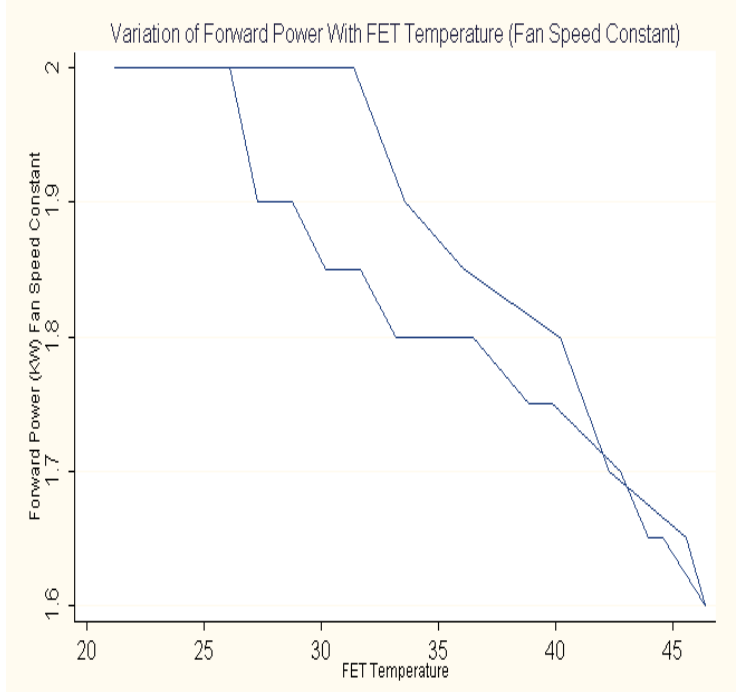

Fig 3.1: Variation of forward power with FET temperature (Fan speed constant)

The calculated total area of the Figure 3.1 is $13.32775 \mathrm{~cm}^{2}$. Relating the power loss to the area of the Figure 3.1 in regard to temperature change,

$$
P_{1}=\frac{\text { Area }}{Q_{2}-Q_{1}}
$$

Where $\mathrm{P}_{1}$ is power, $\mathrm{Q}_{1}$ is the lower temperature, and $\mathrm{Q}_{2}$ is the upper (maximum) temperature measured.

Hence

$$
\begin{aligned}
P_{1} & =\frac{13.32775}{46.4-21.2} \\
P_{1} & =0.5289 \mathrm{~cm}^{2} /{ }^{\circ} \mathrm{C}
\end{aligned}
$$

Hence percentage loss of power is $52.89 \%$ (in this part, note that the $\mathrm{Y}$ axis has units in $\mathrm{kW}$ so that $\mathrm{P}_{1}=0.5289 \mathrm{KW} /{ }^{\circ} \mathrm{C}$ )

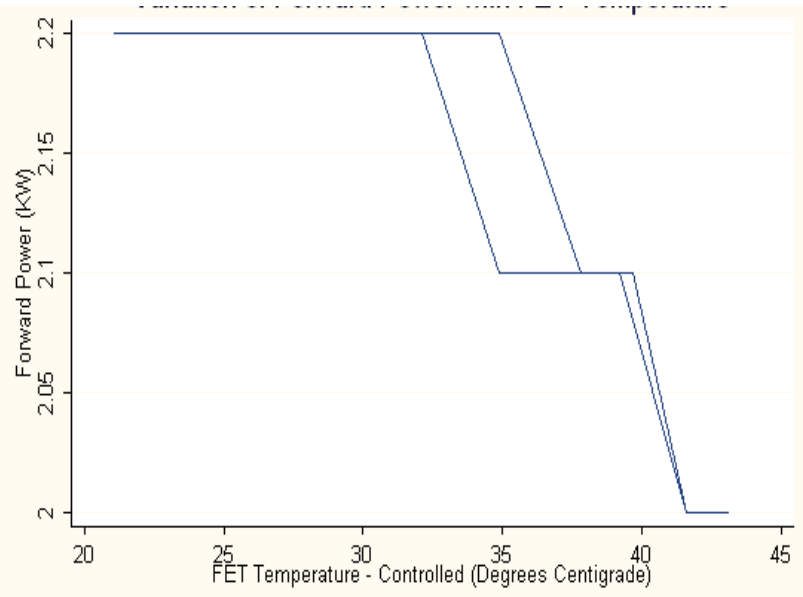

Fig 3.2: Variation of forward power with auto-controlled FET temperature

The calculated total area of the Figure 3.2 is $5.58 \mathrm{~cm}^{2}$. Relating the power loss to the area of the Figure 3.2 in regard to temperature change

$$
P_{1}=\frac{\text { Area }}{Q_{2}-Q_{1}}
$$

Where $P_{1}$ is power, $Q_{1}$ is the lower temperature, and $Q_{2}$ is the upper (maximum) temperature measured.

Hence

$$
\begin{aligned}
P_{1} & =\frac{5.58}{43.1-21.1} \\
P_{1} & =0.2536 \mathrm{~cm}^{2} /{ }^{\circ} \mathrm{C}
\end{aligned}
$$

Hence percentage loss of power is $25.36 \%$, giving a loss of $0.254 \mathrm{KW} /{ }^{\circ} \mathrm{C}$ of temperature rise. From the analysis above, it is clearly shown that the microprocessor-controlled FET temperature contributed much in maintaining the output power of the transmitter as compared to the unintelligent controlled FET temperature. The ratio between $\mathrm{P}_{1}$ and $\mathrm{P}_{2}$ is 2.08. Hence the microprocessor controlled temperature was a factor of 2 better in stabilizing output power than the fan alone. It's also clearly shown that the power recovery time is less.

\subsection{Validity of the System}

Validity test was conducted to ascertain the significance of the collected data in regard to the dependent and independent variables in maintaining the RF output power and signal quality.

This involved:

i. The validity of monitoring ambient air temperature and power transistors temperature.

ii. The ability of auto varying the motor speed hence varying the ambient flow rate according to the prevailing temperature. 
iii. The ability of the system to record data within 5 seconds and display it on the LCD in a readable form.
Hence regression analysis was done on the variables using the Least Square method to get the best fit straight line with the data from Table 3.0[10].

Table 3.0 regression analysis

\begin{tabular}{|l|l|l|l|l|}
\hline $\begin{array}{l}\text { Microprocessor- } \\
\text { controlled FET } \\
\text { Temperature } \\
(\mathbf{x})\end{array}$ & $\begin{array}{l}\text { Squared value of } \\
\text { Microprocessor- } \\
\text { controlled FET } \\
\text { Temperature } \\
\left(\mathbf{x}^{2}\right)\end{array}$ & $\begin{array}{l}\text { Microprocessor- } \\
\left.\text { controlled Q } \mathbf{m}^{3} / \mathbf{s}\right) \\
(\mathbf{y})\end{array}$ & $\begin{array}{l}\text { Squared value of } \\
\text { Microprocessor- } \\
\text { controlled Q } \\
\left(\mathbf{y}^{2}\right)\end{array}$ & $\mathbf{3 0 3 8 . 5 6 7 2}$ \\
\hline 21.1 & 445.21 & 55.1232 & 4234.8858 & 1163.0995 \\
\hline 25.4 & 645.16 & 65.076 & 4497.9235 & 1652.9304 \\
\hline 26.3 & 691.69 & 67.06656 & 4768.8858 & 1763.8505 \\
\hline 27.3 & 745.29 & 69.05712 & 5047.7728 & 1885.2594 \\
\hline 28.7 & 823.69 & 71.04768 & 5629.3208 & 2039.0684 \\
\hline 30.1 & 906.01 & 75.0288 & 6242.5675 & 2258.3669 \\
\hline 32.5 & 1056.25 & 79.00992 & 6887.5127 & 2567.8224 \\
\hline 34.9 & 1218.01 & 82.99104 & 7914.3656 & 2896.3873 \\
\hline 37.8 & 1428.84 & 88.96272 & 8695.5774 & 3362.7908 \\
\hline 39.7 & 1576.09 & 93.25008 & 9394.4479 & 3702.0282 \\
\hline 41.6 & 1730.56 & 96.92496 & 10182.037 & 4032.0783 \\
\hline 43.1 & 1857.61 & 100.90608 & 9784.2801 & 4349.0521 \\
\hline 42.1 & 1772.41 & 98.91552 & 9394.4479 & 4164.3434 \\
\hline 41.6 & 1730.56 & 96.92496 & 8638.5574 & 4032.0783 \\
\hline 39.2 & 1536.64 & 92.94384 & 3643.3985 \\
\hline
\end{tabular}

\begin{tabular}{|l|l|l|l|l|}
\hline$\sum x=511.4$ & $\sum x^{2}=18164.02$ & $\sum y=1233.2285$ & $\sum y^{2}=104351.1493$ & $\sum x y=43512.5545$ \\
\hline
\end{tabular}

The regression equation is $y=a_{0}+a_{1} x$

Evaluating for the regression equation

$a_{1}=\frac{S_{x y}}{S_{x x}}=\frac{1467.6848}{728.6893}=2.0141$

$$
\begin{aligned}
& S_{x x}=\sum x^{2}-\frac{\left(\sum x\right)^{2}}{n}=18164.02-\frac{(511.4)^{2}}{15} \\
& =728.6893
\end{aligned}
$$$$
\bar{y}=\frac{1233.2285}{15}=82.2152
$$

$S_{y y}=\sum y^{2}-\frac{\left(\sum y\right)^{2}}{n}=104351.1493-\frac{(1233.2285)^{2}}{15}$

$$
\bar{x}=\frac{511.4}{15}=34.0933
$$

$=2960.9837$

$a_{0}=\bar{y}-a_{1} \bar{x}$

$$
\begin{aligned}
& =82.2152-(2.0141 \times 34.0933) \\
& =13.5479
\end{aligned}
$$

$S_{x y}=\sum x y-\frac{\sum x \sum y}{n}=43512.5545-\frac{511.4 \times 1233.2285}{15}$

$$
=13.55
$$

$=1467.6848$ 
Thus the regression coefficient $r^{2}$ is as shown

$$
\begin{aligned}
& r^{2}=\frac{S_{x y}^{2}}{S_{x x} \times S_{y y}}=\frac{1467.6848^{2}}{728.6893 \times 2960.9837} \\
& =0.998360
\end{aligned}
$$

Hence, evaluating the value of y using the equation

$$
\begin{gathered}
y=a_{0}+a_{1} x \\
y_{1}=13.55+(2.01 \times 21.1)=55.96=56
\end{gathered}
$$

Using the formula for $y$, the rest are;

\begin{tabular}{|l|l|}
\hline $\mathrm{y}_{1}=56$ & $\mathrm{y}_{9}=90$ \\
\hline $\mathrm{y}_{2}=65$ & $\mathrm{y}_{10}=93$ \\
\hline $\mathrm{y}_{3}=66$ & $\mathrm{y}_{11}=97$ \\
\hline $\mathrm{y}_{4}=68$ & $\mathrm{y}_{12}=100$ \\
\hline $\mathrm{y}_{5}=71$ & $\mathrm{y}_{13}=98$ \\
\hline $\mathrm{y}_{6}=74$ & $\mathrm{y}_{14}=97$ \\
\hline $\mathrm{y}_{7}=79$ & $\mathrm{y}_{15}=92$ \\
\hline $\mathrm{y}_{8}=84$ & \\
\hline
\end{tabular}

Evaluating for the regression equation yields a regression coefficient of $\mathrm{r}^{2}=0.998360$

Figure 3.3 shows the regression line depicting the FET temperature and flow rate relationship.

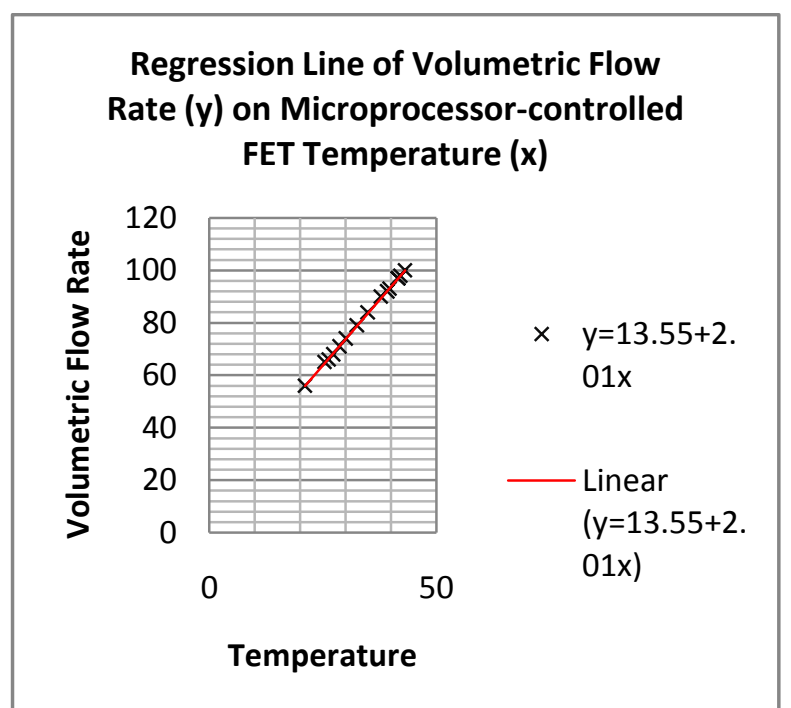

Fig 3.3: Regression Line of Volumetric Flow Rate (Y) on Microprocessor-controlled FET temperature (x)

From the graph (Figure 3.3), a change in Temperature produces a change in volumetric flow rate i.e., increased flow rate, showing that the microprocessor responded positively to increase in temperature.

\subsection{Discussion}

From the analysis, it is clearly shown that, the microprocessor controlled power transistors (field effect transistors - FET) temperature, contributed much in maintaining the radio frequency output power as compared to the unintelligent power transistor temperature controller. The ratio between $\mathrm{P}_{1}$ and $\mathrm{P}_{2}$ referring to figures 3.1 and 3.2 is 2.08. Hence the microprocessor controlled temperature was by a factor of 2 better in stabilizing the RF output power than the fan running at a constant speed. This meant high strength of the carrier frequency. Thus improved signal to noise ratio was achieved, leading to a high quality signal.

Referring to figure 3.0, the microprocessor controller minimised the RF output power fluctuations as compared to the fan running at constant speed.. This led to maintaining the range of radio waves thus better signal coverage.

Temperature being fully controlled indicates that, power transistors are not pushed to conduct at the saturation region or beyond the cut off region. This means an increased lifespan of the power transistors, hence minimal cost of running a transmitter.

Using the least square method analysis, gave a regression coefficient $\left(r^{2}\right)$ of 0.99836 . This showed the positive relationship between the FET temperature and ambient air flow rate. Thus much of the variation in temperature can be controlled by the volumetric flow rate as it caters for $99 \%$ of the variations.

\section{CONCLUSIONS}

The FET microprocessor temperature controller increased the effectiveness of the transmitter by stabilizing the Forward Power. This is because there is minimal reduction of radio frequency power and smaller recovery time in response to temperature changes. This indicates that by use of the microcontroller-based temperature controller, there is increased signal coverage and better quality signal is achieved since signal amplitude is well maintained and noise suppressed.

Energy saving is also achieved, since the intelligent temperature controller reduces power consumption at low temperatures and increases consumption at high temperatures to enhance temperature regulation.

\section{REFERENCES}

[1]. Yamamoto T; Shah L.S. (2007). Design of a Performance-Adaptive PID controller. International conference on Networking sensing and control, IEEE 2007 PP 547-552

[2]. Yun, L.K. Heong, A. and Gregory, C.Y. PID control system analysis and Design-problems, Remedies and Future Directions. IEEE control system magazine, February 2006 P.P. 32-41. 
[3]. Theraja (2002) Electrical Measurements and Instrumentation, New Age International Publishers, New Delhi, India.

[4]. Sawhney, A.K, and Sawhney, P. (2007) Electrical and Electronic Measurements and Instrumentation $17^{\text {th }}$ Edition, Dhnpat Rai and Co. (P) Ltd educational and technical Publishers Delhi, India

[5]. Broadcast Electronics inc, (2008), Solid state Amplification, (www.bdcast.com), Accessed $5^{\text {th }}$ Sept 2010.

[6]. AVRStudio4, 2006, Atmel Corporation (www.atmel.com), Accessed 12 $2^{\text {th }}$ Dec 2010.

[7]. Chao M, Qingli L, Zhongyuan L, Yu J. Low cost AVR Microcontroller development kit for undergraduate laboratory and take-home pedagogies. $2^{\text {nd }}$ international conference on education Technology and Computer (ICETC), Shangai, 2010; 1:35-38

[8]. Korber S, James V, interesting Application of Atmel AVR microcontrollers. IEEE Euromicro symposium on Digital system Design (DS D04). France. 2004

[9]. Intercooled STATA 8.0 (2003), (www.stata.com), Accessed $5^{\text {th }}$ August 2011.

[10]. Kothari, C.R (2008), Research Methodology: Methods and Techniques, New age International (P) Limited, Publishers, New Delhi 